\title{
Comparison of Microwave Assisted Thermo-Chemical Procedures in the Production of Adsorbents for Wastewater Treatment
}

\author{
Cibele C. O. Alves, Adriana S. Franca, and Leandro S. Oliveira
}

\begin{abstract}
Agricultural residues were evaluated as raw material in the production of adsorbents for phenol removal from aqueous solutions. A comparative evaluation of acid and basic activating agents is presented. Adsorption kinetics and equilibrium were satisfactorily described by the pseudo second-order and Freundlich models, respectively. Adsorption tests showed that the prepared adsorbents presented higher adsorption capacity than activated carbons produced from other agricultural residues, confirming that this type of waste material is a suitable candidate for use in the production of adsorbents.
\end{abstract}

Index Terms-Adsorption, agricultural wastes, phenol removal.

\section{INTRODUCTION}

Many industrial wastewaters contain organics which are difficult, or sometimes impossible, to remove by conventional biological treatment processes. Phenol is the base structure unit of a variety of synthetic organic compounds. It usually enters water sources from various chemicals, pesticides, paper, pulp and dye manufacturing industries, and wastewaters from industries such as gas and coke, resin, tanning, textile, plastic, rubber, pharmaceutical and petroleum. The appreciable solubility of this compound in water, combined with its high reactivity and resistance to biodegradation, make it an important toxic material listed as a priority pollutant to be monitored in the aquatic environment [1].

There are many methods such as oxidation, precipitation, ion exchange and solvent extraction to remove phenolic materials from aqueous solution. Nevertheless, adsorption using activated carbon (AC) has proved to be very effective in treating effluents [2]. Besides, AC adsorption has been cited by the United States Environmental Protect Agency (EPA) as being one of the best available environmental control technologies [2]. However, the widespread use of AC adsorption is restricted because of the high cost of conventional and commercial carbons. Therefore, in recent years, many researchers have tried to produce ACs using renewable and cheaper precursors which are mainly

Manuscript received September 25, 2014; revised January 19, 2015. This work was supported by the following Brazilian Goverment Agencies: CNPq (Grant \# 306139/2013-8) and FAPEMIG (Grant \# CEX-APQ-04168-10 and PPM-00505-13).

Cibele C. O. Alves, Adriana S. Franca, and Leandro S. Oliveira are with DEMEC, Universidade Federal de Minas Gerais, Av. Antônio Carlos 6627, Belo Horizonte, MG, 31270-901, Brazil (e-mail: cibeleoliveiraalves@gmail.com, adriana@demec.ufmg.br, leandro@demec.ufmg.br). industrial and agricultural by-products (lignocellulosics) [3]-[5].

The basic processes of transforming lignocellulosic material into ACs can be divided into physical or chemical activation. Physical activation consists of thermal treatment of the material, usually carried out in a two-step process: carbonization in an inert atmosphere to produce the charcoal, followed by a heat treatment in the presence of $\mathrm{CO}_{2}$ or steam to increase the porosity of the material (activation). The chemical activation, on the other hand, is carried out by means of impregnation of the carbon structure with an activating agent followed by heat treatment. In this case, both carbonization and activation steps can be carried out simultaneously. This process is usually considered to be more advantageous in comparison to physical activation, given that it usually occurs at lower temperatures, leads to higher carbon yields, and allows better control of the development of microporosity [6].

Microwaves have been extensively employed as an alternative heating method and several studies have demonstrated that this technique can be successfully employed in the production of ACs [7]. Some of the advantages of this technique over conventional heating for the production of ACs are reduction in processing time with consequent reduction in energy consumption; reduction or even elimination of the amount of gases employed for the treatment; and more efficient carbonization, given the heating mechanism is internal and volumetric as opposed to heat transfer from the surface towards the interior in the case of conventional processing [7]. Other advantages include higher heating rates, no direct contact between heating source and the heated materials, possibility of selective heating, precise control of temperature, small equipment size and reduced amounts of waste.

In view of the aforementioned, the objective of this study was to produce activated carbons based on lignocellulosic materials by microwave-based thermo-chemical activation. The employed lignocellulosic materials were the following agricultural wastes: spent coffee grounds (CG), coffee husks $(\mathrm{CH})$ and pequi husks $(\mathrm{PH})$. Coffee is the most important agricultural product from Brazil, and such crop generates large amounts of solid residues, adding up to over 2 million tons per year, mainly comprised of coffee husks $(\mathrm{CH})$ and spent coffee grounds (CG) [8]. Pequi (Caryocar brasiliense Camb.) is a typical fruit found in the Brazilian cerrado. The pulp and seed, representing only $8 \%$ of the total fruit weight, are the fruit parts that are consumed and employed for preparation of food products, whereas the remaining husks (PH) are discarded [9]. All the previously mentioned solid residues present environmental problems in terms of 
adequate disposal, given their limited applications as animal feed, silage or energy source, thus reinforcing the need for proposals of alternative uses.

\section{MethodOLOGY}

\section{A. Adsorbent Preparation}

The raw materials were submitted to preliminary carbonization tests employing a household microwave oven (Panasonic NN6460A) at 800W. The conditions that provided homogeneous carbonization without ash formation are described as follows. Carbonization occurred in $2 \mathrm{~min}$ cycles. In 40-second intervals between cycles, each sample was stirred by hand with the aid of a glass rod. The required number of cycles needed for carbonization of the samples were 4, 2 and 3 s for $\mathrm{CG}, \mathrm{CH}$ and $\mathrm{PH}$, respectively. The charcoals were washed with distilled water, dried at $110^{\circ} \mathrm{C}$ for $24 \mathrm{~h}$, mixed with the activating agent and then submitted to $24 \mathrm{~h}$ heat treatment in an oven $\left(60^{\circ} \mathrm{C}\right)$. Afterwards, the produced adsorbents were cooled at room temperature and washed with distilled water until $\mathrm{pH} 7$. The solids were dried at $110^{\circ} \mathrm{C}$ for $24 \mathrm{~h}$ and ground to particle diameters ranging from 0.15 to $0.43 \mathrm{~mm}$. Each produced adsorbent was named as acronym of raw material $(\mathrm{CG}, \mathrm{CH}$ and $\mathrm{PH}$ ) followed by chemical nomenclature corresponding to the activating agent used $\left(\mathrm{KOH} 20 \%, \mathrm{NaOH} 20 \%, \mathrm{H}_{3} \mathrm{PO}_{4} 1 \mathrm{M}, \mathrm{ZnCl}_{2} 1 \mathrm{M}\right.$, $\mathrm{NaHCO}_{3} 5 \%, \mathrm{Na}_{2} \mathrm{CO}_{3} 20 \%$ and $\mathrm{K}_{2} \mathrm{CO}_{3} 20 \%$ ), totaling eight types of carbons for each precursor material, included the control samples, which corresponded to each produced charcoal prior to the chemical treatment stage. The AC yield, defined as the weight of dried adsorbent to the weight of dry raw material, was calculated according to equation:

$$
\operatorname{yield}(\%)=\frac{W_{1}}{W_{\mathrm{o}}} \times 100
$$

where $W_{\mathrm{o}}$ is the precursor weight and $W_{1}$ is the resulting adsorbent mass.

\section{B. Adsorption Tests}

Batch experiments of adsorption were performed in 250 $\mathrm{mL}$ Erlenmeyer flasks, with the flasks being agitated on an orbital shaker at $100 \mathrm{rpm}$. In all sets of experiments, the adsorbent was thoroughly mixed with $100 \mathrm{~mL}$ phenol (Phe). Initial Phe concentration was $600 \mathrm{mg} \mathrm{L}^{-1}$ at a fixed adsorbent concentration $\left(10 \mathrm{~g} \mathrm{~L}^{-1}\right)$. All tests were performed in two replicates. $2 \mathrm{~mL}$ aliquots were taken from the Erlenmeyer flasks at pre-specified time intervals and phenol concentration was determined by a UV-Vis spectrophotometer (Hitachi U-2010) at $269 \mathrm{~nm}$. The amount of phenol adsorbed, $q(\mathrm{mg} / \mathrm{g})$, was calculated by:

$$
q=\frac{\left(C_{\mathrm{o}}-C\right) V}{W}
$$

where $C_{\mathrm{o}}$ and $C\left(\mathrm{mg} . \mathrm{L}^{-1}\right)$ are the liquid-phase concentrations of Phe at initial and sampling times, respectively; $V$ is the volume of the solution and $W$ is the mass of dry adsorbent.

\section{Adsorbent Characterization}

The surface structure of the prepared adsorbents that presented better performances in the equilibrium tests was investigated using Fourier Transform Infrared (FTIR) spectroscopy, before and after chemical activation by $\mathrm{NaOH}$ $20 \%$. The FTIR spectra were obtained and recorded on a FTIR spectrometer (IRAffinity-1, Shimadzu, Japan) operating in the range of $600-4000 \mathrm{~cm}^{-1}, 4 \mathrm{~cm}^{-1}$ resolution.

\section{RESULTS AND DISCUSSION}

\section{A. Adsorbent Yield}

The yields of the prepared activated carbons are presented in Fig. 1 and ranged from $25-40 \%$ for spent coffee grounds, $11-29 \%$ for coffee husk and $4-12 \%$ for pequi husks. Overall AC yields were lower for the ACs submitted to chemical activation in comparison to the original charcoals, regardless of the precursor material. During the impregnation step the activating chemical agent will promote hydrolysis and simultaneous swelling of the carbon structure, while occupying a volume which inhibits the shrinking of the structure during heat treatment. The macroscopic effects are increase in porosity and decrease of carbon mass [6].

Among the evaluated materials, SG presented the highest yields. This type of residue is highly fibrous, presenting cellulose contents from 22 to $28 \%$ (dry matter basis), which are similar to coffees husks (23\% dry matter basis). Nevertheless, the higher yields obtained for adsorbents based on spent coffee grounds can be associated to its higher fixed carbon content compared to coffee husk adsorbents. The fixed carbon content is inversely related to volatile matter and ash content, which explains the lower yields in coffee husks. The calorific value of agricultural wastes, on the other hand, is directly related to the fixed carbon content. The calorific value of coffee husks $(3.93 \mathrm{kcal} / \mathrm{kg}$ dry matter $)$ is significantly small in comparison to spent coffee grounds (6.93 kcal/kg dry matter).

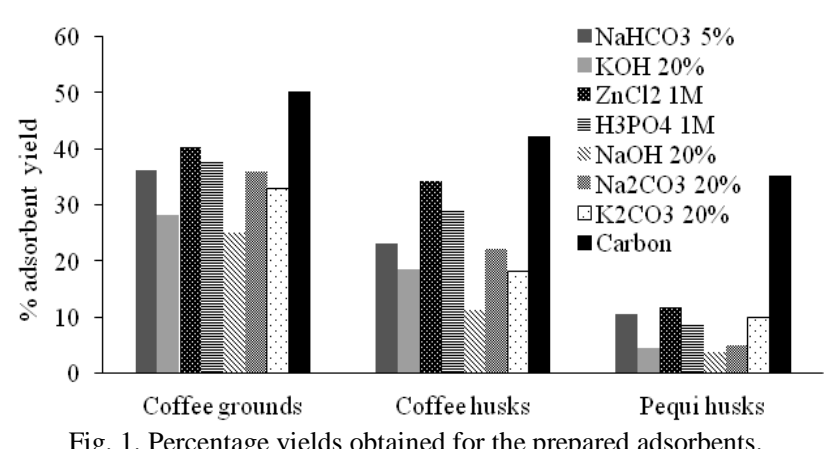

In a recent work [10], spent coffee grounds were thermo-chemically activated with $\mathrm{KOH}$ (4:1 impregnation ratio) at $600^{\circ} \mathrm{C}$ for 1 hour. The obtained carbon yield was $15 \%$, lower than the one obtained in our study employing the same activating agent $(28 \%)$, this being attributed to the use of microwave instead of the conventional carbonization method. These differences in yield occurs because conventional method requires longer carbonization times and higher temperatures than microwave-induced methods, with consequent lower yields.

The adsorbents produced from the pequi husk had the lowest yields and the highest losses (32-40\%) caused by chemical treatment. This is due to its advanced state of senescence and the high pectin content that facilitated the 
breakdown of lignocellulosic structure by activating agents and the soluble fiber leaching in washing process.

\section{B. Effect of Activating Agent}

The results obtained for adsorption capacity varying with time for all the prepared adsorbents are shown in Fig. 2. Results indicated that the contact time needed to reach the adsorption equilibrium of phenol for all waste-based carbons, with or without chemical activation, is approximately $6 \mathrm{~h}$. Therefore, the chosen contact time of $18 \mathrm{~h}$, used in these experiments, was enough to attain equilibrium.

In general, it can be seen that the adsorption of phenol is rapid at the initial stage of the contact period, but it gradually slows down until it reaches equilibrium. The fast adsorption at the initial stage is attributed to the high values of concentration gradient in the beginning of the adsorption processes, representing a significant driving force for phenol transfer between the solution and the adsorbent surface. Such qualitative behavior was has also been reported for phenol adsorption by other materials [11], [12].
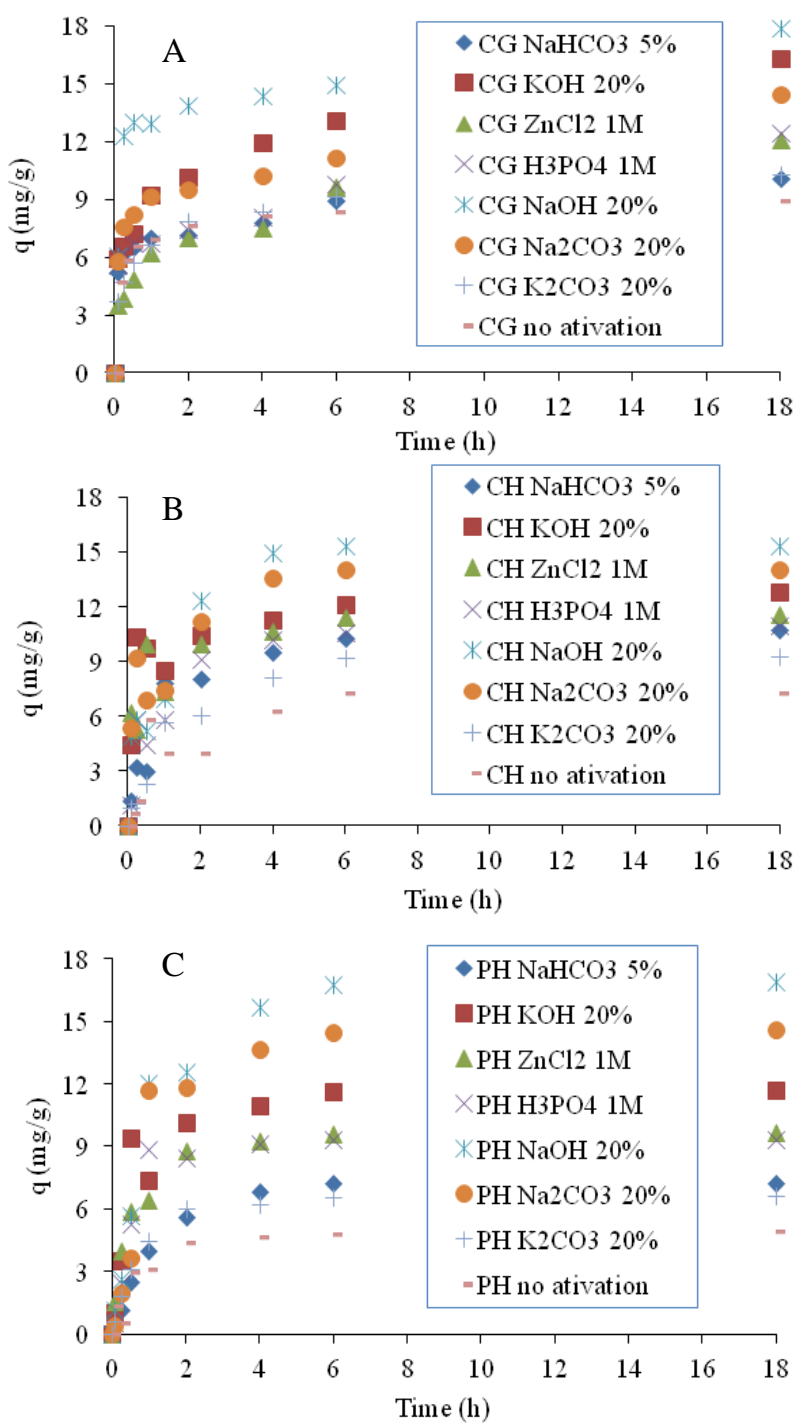

Fig. 2. Adsorption capacity of the prepared adsorbents A) CG; B) CH and C) $\mathrm{pH}$.

The results shown in Fig. 2 also indicated the activating agent has a significant effect on the adsorption capacity. The activation by acidic agents $\left(\mathrm{H}_{3} \mathrm{PO}_{4}\right.$ and $\left.\mathrm{ZnCl}_{2}\right)$ resulted in activated carbons with the highest yield (see Fig. 1) but with moderate adsorption capacity. The activating agents that resulted in adsorbents with great phenol adsorption capacity were $\mathrm{NaOH}$, followed by $\mathrm{KOH}$ and $\mathrm{Na}_{2} \mathrm{CO}_{3}$.

Chemical activation not only promotes chemical changes to the charcoal matrix but also physical changes by favoring the creation of pores (by volatilization of organic matter) and, depending on the chemical agent, further enlargement of existing pores. In altering the chemical makeup of the charcoal surface, the chemical agent invariably alters the final chemical functionality of the activated carbon surface and, hence, its affinity to specific adsorbates. Different activating mechanisms are proposed in the literature for each of the aforementioned chemical agents during carbonization. From a physical point of view, agents like $\mathrm{KOH}$ and $\mathrm{NaOH}$ promote a widening of the micropores produced by the carbonization of the precursor, $\mathrm{ZnCl}_{2}$ is associated with further developing small mesoporosity, and $\mathrm{H}_{3} \mathrm{PO}_{4}$ usually leads to a more heterogeneous pore size distribution [6]. Regarding the chemical changes promoted by the activating agents, carbon surface basicity is associated with the presence of carbonyls, chromene, pyrones and oxygen-free Lewis-type structures, whereas the acidic behavior is related to oxygen-containing groups (mainly carboxylic, anhydrides, lactonic and phenolic). Basic surfaces are favorable for phenol adsorption, as well as the microwave irradiation and activation by basic agents, because they promote the incorporation of basic groups [6]. Given that, regardless of the precursor material, the adsorbents with better performance were the ones activated by $\mathrm{NaOH}$, the remaining tests were conducted with these adsorbents.

\section{Adsorption Kinetics}

The controlling mechanisms of the adsorption processes are usually investigated by fitting pseudo first and second-order kinetic models to the experimental data, generically represented by the following equation:

$$
\frac{d q_{t}}{d t}=k_{n}\left(q_{e}-q_{t}\right)^{n}
$$

where $q_{e}$ and $q_{t}$ correspond to the amount adsorbed per unit mass of adsorbent $\left(\mathrm{mg} \mathrm{g}^{-1}\right)$ at equilibrium and at time $t$, respectively, $k_{n}$ corresponds to the rate constant for $n^{\text {th }}$ order adsorption. The integrated forms of the equations are:

First-order kinetics $(n=1)$ :

$$
q_{t}=q_{e}\left(1-e^{-k_{1} t}\right)
$$

Second-order kinetics $(n=2)$ :

$$
\frac{t}{q_{t}}=\frac{1}{k_{2} q_{e}^{2}}+\frac{t}{q_{e}}
$$

Evaluation of each model's ability to predict the experimental data was based on the regression correlation coefficient values $\left(r^{2}\right)$ and the following error measure:

$$
\operatorname{RMS}(\%)=100 \sqrt{\sum\left[\left(q_{t, \text { est }}-q_{t, \text { exp }}\right) / q_{t, \text { exp }}\right]^{2}} / N
$$

where $N$ is the number of experimental points in each $q_{t}$ vs. $t$ curve; $q_{t, \exp }$ and $q_{t, \text { est }}$ represent the experimental and model-estimated values of the equilibrium capacity, respectively. 


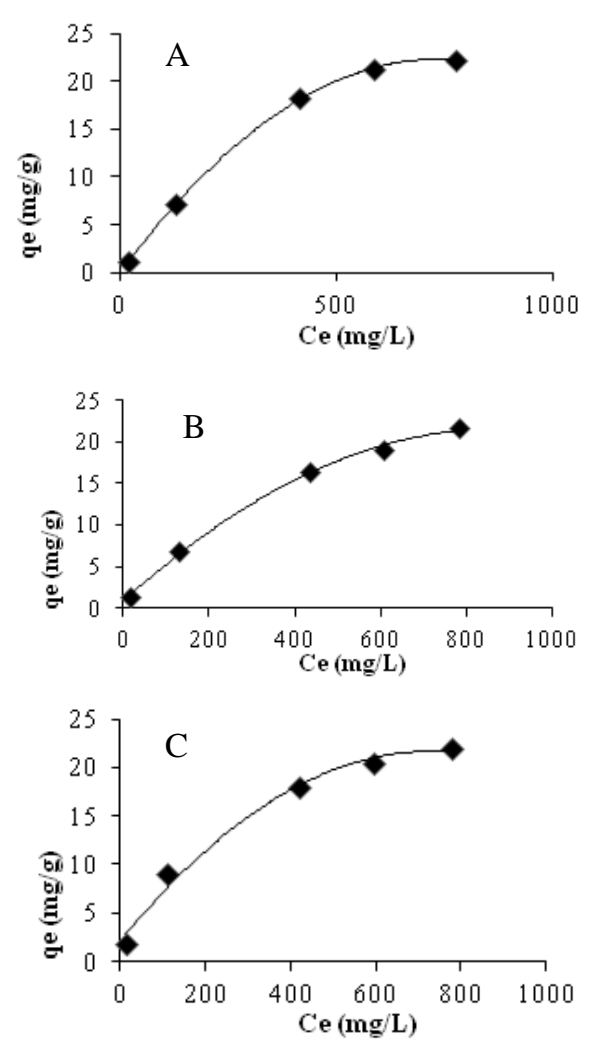

Fig. 3. Adsorption isotherms: A) $\mathrm{CG}$; B) $\mathrm{CH}$ and $\mathrm{C}) \mathrm{pH}$.

Results for the non-linear fits of the kinetic models and their estimates for equilibrium adsorption capacity are shown in Table I. The pseudo-second-order model provided higher $R^{2}$ values and lower values of RMS error in carbons produced from $\mathrm{CG}$ and $\mathrm{CH}$. This model has been successfully applied for description of adsorption kinetics of several adsorbates, describing both chemisorption and ion exchange mechanism [12]. An opposite behavior was observed for phenol adsorption by carbons obtained from $\mathrm{PH}$, where the first order model provided a better fit. This model usually provides a good description of adsorption processes where physical interactions are predominant. The behavior difference in adsorption kinetic process can be attributed to differences in raw material sources.

\section{Adsorption Equilibrium}

The equilibrium isotherms obtained at $25^{\circ} \mathrm{C}$ are displayed in Fig. 3. The shapes of the curves (concavity towards the abscissa axis) indicate favorable adsorption, regardless of the precursor material employed. Notice that all prepared adsorbents presented similar performances in terms of the total amount adsorbed as the initial phenol concentration was increased ( $22 \mathrm{mg} / \mathrm{g}$ adsorption capacity). However, from the isotherms, it can be seen that isotherm curvature was not the same, being steeper for $\mathrm{CG}$ and thus indicating that adsorption would be more favorable for that adsorbent.

Isotherms were also evaluated in terms of fitting both twoand three-parameter adsorption models [13]. Details on the tested models and calculated parameters (obtained by non-linear regression based on least squares minimization, $p$ $<0.05)$ are shown in Table II. Model selection was based on highest $R^{2}$ values coupled with the lowest difference between calculated and experimental $q_{e}$ values, evaluated according to the following root mean square error measure:

$$
R M S=100 \sqrt{\sum\left[\left(q_{e, e s t}-q_{e, e x p}\right) / q_{e, e x p}\right]^{2}} / N
$$

where $q_{e, \text { exp }}$ and $q_{e, \text { est }}$ are the experimental and calculated equilibrium adsorbent amounts, respectively, and $N$ corresponds to the number of experimental isotherm points.

TABLE I: KINETIC PARAMETERS FOR PHENOL ADSORPTION

\begin{tabular}{|c|c|c|c|c|c|c|}
\hline & \multicolumn{6}{|c|}{ Adsorbent } \\
\hline & $\overline{C C^{a}}$ & $\overline{\mathrm{CG}^{\mathrm{b}}}$ & $\overline{\mathrm{C} \mathrm{CH}^{\mathrm{a}}}$ & $\overline{\mathrm{CH}^{\mathrm{b}}}$ & $\overline{\mathrm{PH}}{ }^{\mathrm{a}}$ & $\mathrm{PH}^{\mathrm{b}}$ \\
\hline $\begin{array}{l}q_{e}\left(\mathrm{mg} \mathrm{g}^{-1}\right) \\
(\text { experimental })\end{array}$ & 8.943 & 17.875 & 7.273 & 15.342 & 4.928 & 17.875 \\
\hline \multicolumn{7}{|l|}{$\begin{array}{l}\text { Pseudo } \\
\text { first-order }\end{array}$} \\
\hline$\overline{k_{1}\left(\mathrm{~h}^{-1}\right)}$ & 8.180 & 4.969 & 0.814 & 0.866 & 1.306 & 0.942 \\
\hline $\begin{array}{l}q_{e}\left(\mathrm{mg} \mathrm{g}^{-1}\right) \\
\text { (estimated) }\end{array}$ & 7.762 & 14.636 & 7.332 & 15.235 & 4.792 & 16.489 \\
\hline$r^{2}$ & 0.912 & 0.921 & 0.976 & 0.895 & 0.930 & 0.981 \\
\hline RMS (\%) & 3.872 & 3.493 & 9.301 & 10.69 & 16.82 & 4.085 \\
\hline \multicolumn{7}{|l|}{$\begin{array}{l}\text { Pseudo } \\
\text { second-order }\end{array}$} \\
\hline$k_{2}\left(\mathrm{~g} \mathrm{mg}^{-1} \mathrm{~h}^{-1}\right)$ & 1.441 & 0.4133 & 0.260 & 0.075 & 0.327 & 18.69 \\
\hline $\begin{array}{l}q_{e}\left(\mathrm{mg} \mathrm{g}^{-1}\right) \\
\text { (estimated) }\end{array}$ & 8.241 & 15.785 & 7.579 & 16.693 & 5.288 & 0.060 \\
\hline$r^{2}$ & 0.970 & 0.950 & 0.991 & 0.905 & 0.930 & 0.975 \\
\hline RMS (\%) & 1.860 & 2.995 & 8.230 & 7.799 & 20.95 & 7.731 \\
\hline
\end{tabular}

a no activation; ${ }^{\mathrm{b}}$ activation with NAOH $20 \%$

TABLE II: ADSORPTION ISOTHERM MODELS AND FITTING PARAMETERS

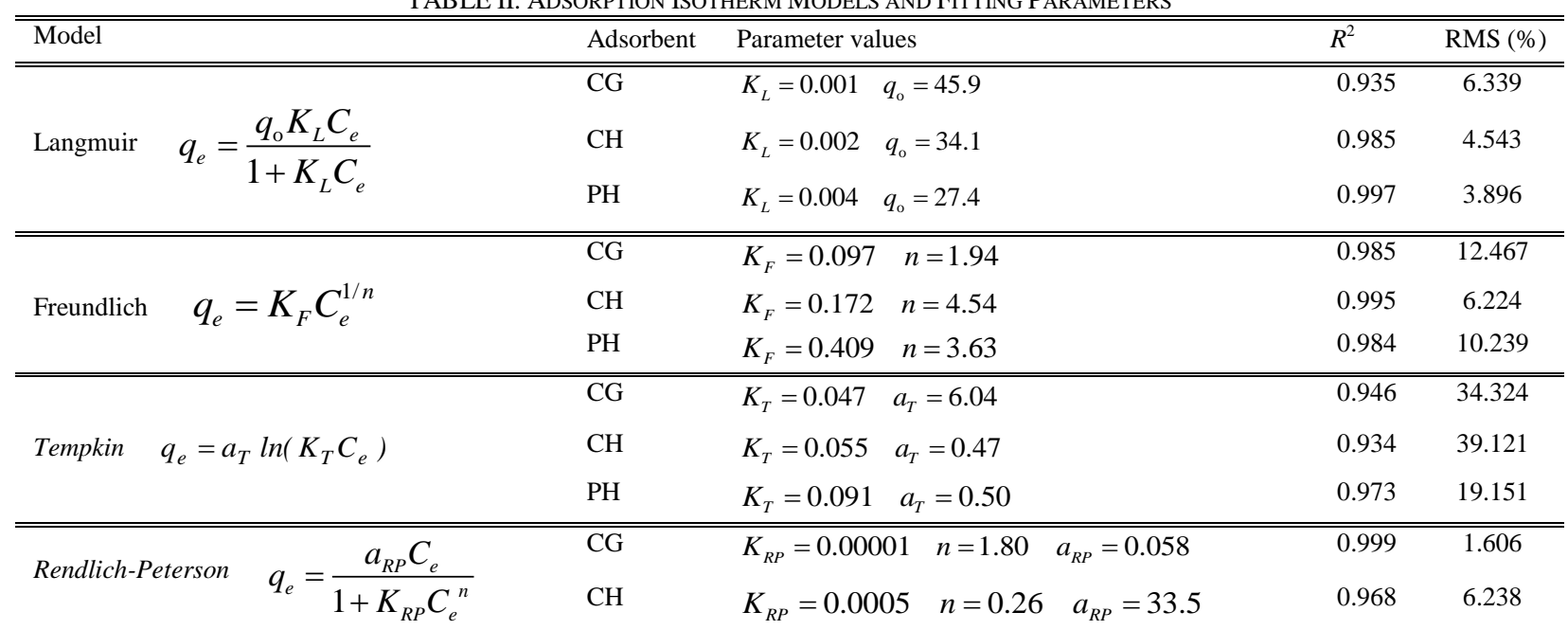




\begin{tabular}{|c|c|c|c|c|}
\hline \multirow{4}{*}{ Koble-Corrigan $\quad q_{e}=\frac{a_{K C} C_{e}^{n}}{1+K_{K C} C_{e}^{n}}$} & $\mathrm{PH}$ & $K_{R P}=0.016 \quad n=0.85 \quad a_{R P}=0.160$ & 0.999 & 0.908 \\
\hline & CG & $\begin{array}{llll}K_{K C}=0.0011 & n=1.08 & a_{K C}=0.044\end{array}$ & 0.999 & 2.801 \\
\hline & $\mathrm{CH}$ & $K_{K C}=0.0011 \quad n=1.08 \quad a_{K C}=0.044$ & 0.999 & 5.402 \\
\hline & $\mathrm{PH}$ & $K_{K C}=0.0011 \quad n=1.08 \quad a_{K C}=0.044$ & 0.999 & 0.071 \\
\hline \multirow{3}{*}{ Generalized } & CG & 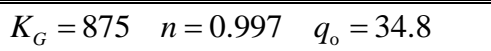 & 0.997 & 3.028 \\
\hline & $\mathrm{CH}$ & $K_{G}=598 \quad n=1.018 \quad q_{\mathrm{o}}=36.1$ & 0.999 & 5.402 \\
\hline & $\mathrm{PH}$ & $K_{G}=159 \quad n=0.886 \quad q_{\mathrm{o}}=31.6$ & 0.999 & 0.071 \\
\hline \multirow{3}{*}{ Langmuir-Freundlic $\quad q_{e}=\frac{q_{\mathrm{o}}\left(K_{L} C_{e}\right)^{n}}{1+\left(K_{L} C_{e}\right)^{n}}$} & 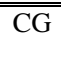 & $\bar{K}_{L F}=0.001 \quad n=1.08 \quad q_{\mathrm{o}}=39.9$ & 0.999 & 2.702 \\
\hline & $\mathrm{CH}$ & $K_{L F}=0.001 \quad n=1.02 \quad q_{\mathrm{o}}=36.1$ & 0.999 & 1.533 \\
\hline & $\mathrm{PH}$ & $K_{L F}=0.006 \quad n=0.89 \quad q_{\mathrm{o}}=31.2$ & 0.999 & 0.071 \\
\hline
\end{tabular}

$q_{e}\left(\mathrm{mg} \mathrm{g}^{-1}\right)$ is the equilibrium adsorption capacity; $C_{e}\left(\mathrm{mg} \mathrm{L}^{-1}\right)$ is the solute concentration in the aqueous solution, after equilibrium; $q_{o}\left(\mathrm{mg} \mathrm{g}^{-1}\right)$ is the maximum adsorption capacity; the remaining constants are empirical parameters associated to each specific model.

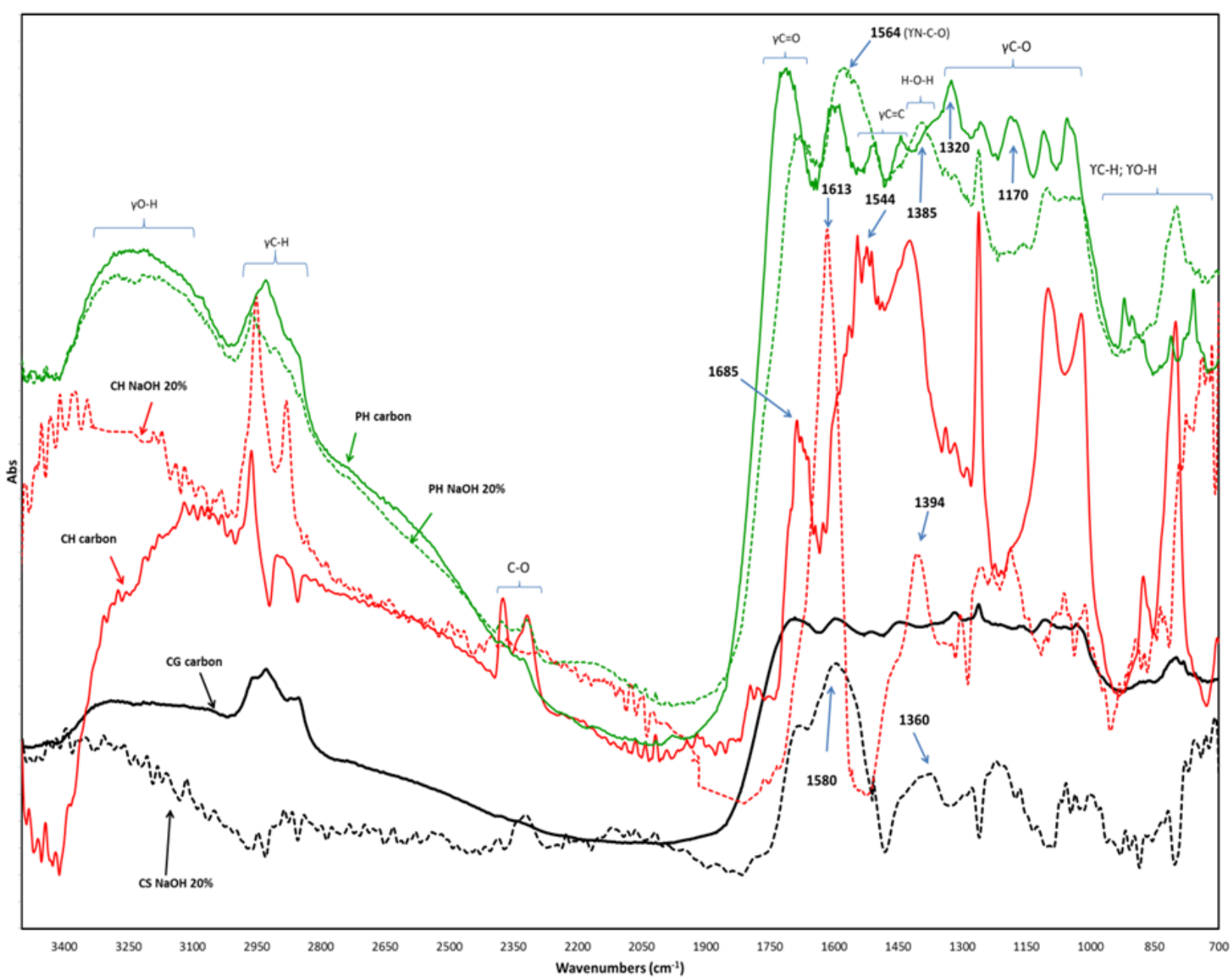

Fig. 4. FTIR spectra of the adsorbents obtained from CG (black lines), $\mathrm{CH}$ (red lines) and PH (green lines), before (solid lines) and after (dashed lines) chemical activation by $\mathrm{NaOH}$.

Among the two-parameter models, Langmuir was the one that provided a better description of the isotherms, but RMS values are too high. The three-parameter model in general provided a better fit, with higher $r^{2}$ values and much lower RMS. Notice that for $\mathrm{CG}$ and $\mathrm{CH}$, the $n$ parameter in Koble-Corrigan, generalized and Langmuir-Freundlich models is close to one, indicating an adsorption behavior typical of microporous materials. This could also explain the higher values of maximum adsorption capacity obtained in comparison to $\mathrm{PH}$, in which adsorption is probably mainly taking place at the surface. Such results are also in agreement with the differences observed in terms of kinetics behavior.

The monolayer maximum adsorption capacity for the prepared adsorbents, based on Langmuir fit, ranged from 27 to $46 \mathrm{mg} / \mathrm{L}$. Such values can be considered satisfactory when compared to maximum capacity data for other residue based adsorbents including tobacco residues, 0.6-18 mg/L [4]; vegetal cords, 5mg/L [14]; coconut shells, $34 \mathrm{mg} / \mathrm{L}$ [15], as well as commercially available activated carbon, $32 \mathrm{mg} / \mathrm{L}$ [16].

\section{E. Adsorbent Characterization}

Fig. 4 shows the FTIR spectra of the carbons derived from coffee husk, spent coffee grounds and pequi husk, all of them before and after chemical activation with $\mathrm{NaOH} 20 \%$. The peaks detected at bandwidths in $2820-3000 \mathrm{~cm}^{-1}$ correspond 
to aliphatic region assigned to $\mathrm{C}-\mathrm{H}$ stretching. In the case of coffee husks, it can be associated to caffeine [17] and, because caffeine is thermally resilient (when bound to a carbon matrix) and chemically inert at the conditions employed in this study for the preparation of activated carbons, its amount remained unaltered and, due to the carbon mass loss resulting from the chemical activation, the associated $\mathrm{C}-\mathrm{H}$ stretching peaks were enhanced. The opposite behaviour was observed for the adsorbents produced from spent coffee grounds and pequi husks. Notice that the coffee extraction procedure, that generates the spent grounds, will deplete the matrix of caffeine and thus the rather small peaks at the $\mathrm{C}-\mathrm{H}$ stretching region are usually attributed to the roasted grounds lipid content (fatty acids fraction), that upon chemical activation completely disappear. The peaks in the wavenumber range of $2290-2390 \mathrm{~cm}^{-1}$ can be attributed to $\mathrm{C}-\mathrm{O}$ group associated with uncompensated atmospheric $\mathrm{CO}_{2}$. The region $1640-1850 \mathrm{~cm}^{-1}$ correspond to $\mathrm{C}=\mathrm{O}$ vibration characteristic of lactones, esters (triglycerides) or aldehydes that decreased intensity or disappeared after activation with $\mathrm{NaOH}$ [18]. Lactones and esters of carboxylic acids are known to undergo hydrolysis under alkaline conditions [19]. The peaks at bandwidths $1540-1610 \mathrm{~cm}^{-1}$ are usually associated to N-C-O symmetric stretch, especially in adsorbents treated with $\mathrm{NaOH}$ [20]. Peaks at $1400-1560 \mathrm{~cm}^{-1}$ are attributed to $\mathrm{C}=\mathrm{C}$ associated with aromatic structure that can be degraded by basic agents. The region $1360-1420 \mathrm{~cm}^{-1}$ encompasses the peaks for $\mathrm{H}-\mathrm{O}-\mathrm{H}$ bending and it can be assumed that, under treatment with $\mathrm{NaOH}$, the aliphatic hydroxyl groups were stimulated to convert to $\mathrm{H}_{2} \mathrm{O}$. The peaks in the wave number range of $950-1350 \mathrm{~cm}^{-1}$ are associated to $\mathrm{C}-\mathrm{O}$ stretching vibration of different functional groups that were left for activated carbons associated with cellulose and lignin region, and the peaks at $700-940 \mathrm{~cm}^{-1}$ are associated to the out-of-plane bending of $\mathrm{C}-\mathrm{H}$ or $\mathrm{O}-\mathrm{H}$ groups [21].

Microwave treatment eliminates the acidic oxygen-containing functional groups and turns the carbon matrix rather basic and very reactive. Moreover, sodium hydroxide is used as the chemical treatment to dissolve lignin. Chemical action and dissolution make $\mathrm{Na}^{+}$connect with phenolic hydroxyl groups $(-\mathrm{OH})$ and carboxyl acid groups $(-\mathrm{COOH})$ of lignin by chemical bonds. So, after the thermo-chemical treatment and the removal of most of the more weakly bonded atoms, a small portion of the more thermally resilient oxygen containing groups (quinone, pirone and chromene) and groups with other heteroatoms (substantially nitrogen) that are basic in nature remain within the aromatic structure of the carbon matrix.

\section{REFERENCES}

[1] S. Arris, M. B. Lehocine, and H. A. Miniai, "Batch adsorption of phenol from industrial waste water using cereal by-products as a new adsorbent," Energy Procedia, vol. 18, pp. 1135-1144, 2012.

[2] R. Baccar, P. Blánquez, J. Bouzid, M. Feki, H. Attiya, and M. Sarrà, "Modeling of adsorption isotherms and kinetics of a tannery dye onto an activated carbon prepared from an agricultural by-product," Fuel Processing Technology, vol. 106, pp. 408-415, February 2013.

[3] C. C. O. Alves, A. S. Franca, and L. S. Oliveira, "Removal of phenylalanine from aqueous solutions with thermo-chemically modified corn cobs as adsorbents," LWT Food Science and Technology, vol. 51, pp. 1-8, April 2013.

[4] M. Kilic, E. Apaydin-Varol, and A. E. Pütün, "Adsorptive removal of phenol from aqueous solutions on activated carbon prepared from tobacco residues: equilibrium, kinetics and thermodynamics," Journal of Hazardous Materials, vol. 189, pp. 397-403, May 2011.

[5] S. Milicevic, T. Boljanac, S. Martinovic, M. Vlahovic, V. Milosevic, and B. Babic, "Removal of copper from aqueous solutions by low cost adsorbent-Kolubara lignite," Fuel Processing Technology, vol. 95, pp. 1-7, March 2012.

[6] L. S. Oliveira and A. S. Franca, "Conventional and non-conventional thermal processing for the production of activated carbons from agro-industrial wastes," in Activated Carbon: Classifications. Properties and Applications, J. F. Kwiatkowski, Ed. New York: Nova Publishers, 2011, pp. 205-238.

[7] A. S. Franca, L. S. Oliveira, A. A. Nunes, and C. C. O. Alves, "Microwave assisted thermal treatment of defective coffee beans press cake for the production of adsorbents," Bioresource Technology, vol. 101, pp. 1068-1074, February 2010.

[8] A. S. Franca, L. S. Oliveira, and A. S. Franca, "Coffee processing solid wastes: current uses and future perspectives," in Agricultural Wastes, G. S. Ashworth and P. Azevedo, Eds. New York: Nova Publishers, 2009, pp. 155-189.

[9] C. C. O. Alves, R. J. Vilela, R. S. Cruvinel, and M. E. T. Prado, "The effects of added sugars and alcohols on the induction of crystallization and the stability of the freeze-dried peki (Caryocar brasiliense Camb.) fruit pulps," LWT-Food Science and Technology, vol. 43, pp. 934-941, July 2010.

[10] M. G. Plaza, A. S. González, C. Pevida, J. J. Pis, and F. Rubiera, "Valorisation of spent coffee grounds as $\mathrm{CO}_{2}$ adsorbents for postcombustion capture applications," Applied Energy, vol. 99, pp. 272-279, November 2012.

[11] E. Lorenc-Grabowska, G. Gryglewicz, and M. A. Diez, "Kinetics and equilibrium study of phenol adsorption on nitrogen-enriched activated carbons," Fuel, vol. 114, pp. 235-243, December 2013.

[12] P. D. Rocha, A. S. Franca, and L. S. Oliveira, "Batch and column studies of phenol adsorption by an activated carbon based on acid treatment of corn cobs," International Journal of Engineering and Technology, vol. 7, pp. 465-469, December 2015.

[13] J. Dron and A. Dodi, "Comparison of adsorption equilibrium models for the study of $\mathrm{Cl}^{-}, \mathrm{NO}^{3-}$ and $\mathrm{SO}_{4}{ }^{2-}$ removal from aqueous solutions by an anion exchange resin," Journal of Hazardous Materials, vol. 190, pp. 300-307, March 2011.

[14] H. Cherifi, S. Hanini, and F. Bentahar, "Adsorption of phenol from wastewater using vegetal cords as a new adsorbent," Desalination, vol. 244, pp. 177-187, August 2009.

[15] K. P. Singh, A. Malik, S. Sinha, and P. Ojha, "Liquid-phase adsorption of phenols using activated carbons derived from agricultural waste material," Journal of Hazardous Materials, vol. 150, pp. 626-641, February 2008.

[16] G. G. Stavropoulos, P. Samaras, and G. P. Sakellaropoulos, "Effect of activated carbons modification on porosity, surface structure and phenol adsorption," Journal of Hazardous Materials, vol. 151, pp. 414-421, March 2008.

[17] N. Reis, A. S. Franca, and L. S. Oliveira, "Discrimination between roasted coffee, roasted corn and coffee husks by diffuse reflectance infrared fourier transform spectroscopy," LWT-Food Science and Technology, vol. 50, pp. 715-722, March 2013.

[18] P. A. M. Mourão, C. Laginhas, F. Custódio, J. M. V. Nabais, P. J. M. Carrott, and M. M. L. R. Carrott, "Influence of oxidation process on the adsorption capacity of activated carbons from lignocellulosic precursors," Fuel Processing Technology, vol. 92, pp. 241-246, February 2011.

[19] R. Gómez-Bombarelli, E. Calle, and J. Casado, "Mechanisms of lactone hydrolysis in neutral and alkaline conditions," The Journal of Organic Chemistry, vol. 78, pp. 6868-6879, June 2013.

[20] M. A. Ahmad and N. K. Rahman, "Equilibrium, kinetics and thermodynamic of Remazol Brilliant Orange 3R dye adsorption on coffee husk-based activated carbon," Chemical Engineering Journal, vol. 170, pp. 154-161, May 2011

[21] Q. S. Liu, T. Zheng, P. Wang, and L. Guo, "Preparation and characterization of activated carbon from bamboo by microwave-induced phosphoric acid activation," Industrial Crops and Products, vol. 31, pp. 233-238, March 2010.

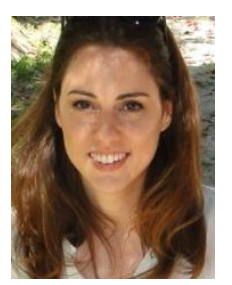

Cibele C. O. Alves was born in 1980. She graduated in food engineering from Centro Universitário de Belo Horizonte, Brazil, in 2004. She completed her Ph.D. degree in food sciences from Universidade Federal de Minas Gerais, Belo Horizonte, Brazil in 2009.

She worked as a post-doctoral fellow at the Department of Mechanical Engineering at Universidade Federal de Minas Gerais, Belo 
Horizonte, Brazil, for the last couple of years. She has published 9 articles in international journals and has presented several research papers related to adsorption at national and international conferences held in Brazil and abroad.

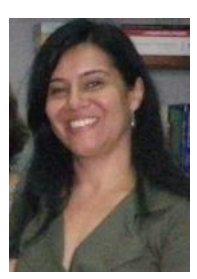

Adriana S. Franca was born in 1966. She graduated in chemical engineering in 1988 and obtained her M.Sc. degree in mechanical engineering in 1991 from Universidade Federal de Minas Gerais, Belo Horizonte, Brazil. She completed her Ph.D. degree in agricultura and biological engineering from Purdue University, USA, in 1995.

She is currently working as an associate professor at the Department of Mechanical Engineering from Universidade Federal de Minas Gerais and also teaches at the graduate course in food sciences. She has published over 75 articles in international journals, 16 book chapters and has presented several research papers at various international conferences. Her research interests include sustainable uses of agricultural residues, coffee chemistry, microwaves, FTIR and others.

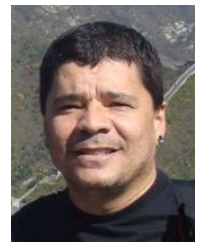

Leandro S. Oliveira was born in 1964. He graduated in chemical engineering in 1988 and obtained his M.Sc. degree in mechanical engineering in 1991 from Universidade Federal de Minas Gerais, Belo Horizonte, Brazil. He completed his Ph.D. degree in agricultural and biological engineering from Purdue University, USA, in 1995.

$\mathrm{He}$ is currently working as an associate professor at the Department of Mechanical Engineering from Universidade Federal de Minas Gerais and is currently the head of the Graduate Program at that Department. Dr. Oliveira also teaches at the graduate course in food sciences. He has published 65 articles in international journals, 11 book chapters and has presented several research papers at various international conferences. His research interests include sustainable uses of solid residues, biofuels, coffee chemistry and others. 